Адрес статьи / To link this article: http://cat.itmo.ru/ru/2021/v6-i2/275

\title{
Взаимоотношения между технологией и культурой: эстетический и культурологический аспекты
}

\author{
Н. А. Хренов \\ Всероссийский государственный институт кинематографии имени С. А. Герасимова, Россия \\ nihrenov@mail.ru
}

\begin{abstract}
Аннотация. Данная статья посвящена истории возникновения разных средств медиа, смысл которой приоткрывается лишь в наше время, когда появляются постсовременные средства медиа в виде интернета. Автор предлагает рассматривать поздние средства медиа, а именно, фотографию, кинематограф, телевидение и т.д. не только как виды искусства, а именно так они до сих пор изучались, и не только как самостоятельные эстетические феномены, а как последовательно возникающие формы единого гештальта, под которым следует подразумевать виртуальную реальность. С этой точки зрения историю медиа можно представлять как состоящую из таких фаз процесса виртуализации, как фотографическая, кинематографическая, телевизионная и т.д. фазы. Процесс виртуализации уходит глубоко в историю, когда возникает язык, письменность и книгопечатание. Основное внимание в статье уделяется тем средствам медиа, которые начались с возникновения в XIX веке фотографии, что стало важной вехой в возникновении знаковых систем уже не в вербальных, а в визуальных формах. В связи с этим автор доказывает, что изучение виртуальной реальности предполагает использование семиотического подхода. Обращаясь к известному в философии техники принципу органопроекции, автор однако приходит к выводу, что телесные формы органопроекции необходимо дополнить духовными, что требует уже философского и эстетического подходов. В связи с этим автор обращается к феноменологии Гегеля, в которой принцип проекции внутреннего на внешнее, предметно-чувственное, в чем заключается смысл гегелевского принципа, предполагает овнешнение уже не телесного, а духовного начала. Как доказывает автор, для эстетического освоения технологий гегелевский принцип является наиболее эффективным. Правда, Гегель не прибегал к понятию «проекция». Этот механизм овнешнения он обозначал как опредмечивание. Последующее обращение к этому понятию привело к выявлению оборотной стороны принципа опредмечивания, связанного с феноменом отчуждения. По мнению автора, более глубокое осмысление развертывающегося с XIX века процесса виртуализации неизбежно подводит к необходимости рассматривать медиа в ракурсе отчуждения, что является оборотной стороной их функционирования.
\end{abstract}

Ключевые слова: медиа, медиареволюция, технологии, цивилизация, знак, семиотический подход, культура, органопроекция, виртуализация, опредмечивание, отчуждение, фотография, кинематограф, телевидение, интернет, письменность, книгопечатание, модерн, гештальт, Сандрар, Капп, Флоренский, Фрейд, Барбье, Шпенглер, Гегель, Гутенберг, Хайдеггер, Манович, Платон, Маркс, Эко 
«Век, который хорошо назван «беспламенным пожаром» у одного поэта; блистательный и погребальный век, который бросил на живое лицо человека глазетовый покров механики, позитивизма и экономического материализма, который похоронил человеческий голос в грохоте машин; металлический век, когда «железный коробок» - поезд железной дороги - обогнал «необгонимую тройку», в которой «Гоголь олицетворял всю Россию», как сказал Глеб Успенский» [1, с. 347].

Наше время производит двойственное ощущение. Причем, видимо, такое ощущение возникает не только сегодня и не только в России. Пожалуй, это характерно для всего прошедшего столетия. Но, судя по всему, такое ощущение перекочевало и в XXI век. Еще в начале 30-х годов прошлого века такое состояние человека фиксирует Х. Ортега-и-Гассет. С одной стороны, это и в самом деле состояние человека, который, как еще считал Кант, достиг своего совершеннолетия и положения, какого не мог достичь человек в предшествующие столетия. Но раз пришло ощущение, что человек, наконец-то, стал совершенным, то это означает, что и время, в котором он существует, - тоже «совершенное время». Наконец-то, в настоящем наступило то самое время, которое до сих пор мыслилось лишь в будущем или же в прошлом, что получало обозначение «золотого века».

Вот по поводу этого наступления «совершенного времени» Х. Ортега-и-Гассет пишет следующее. «Действительно, тридцать лет назад европейцы верили, что жизнь человечества становится наконец такой, какой она должна стать, какой мечтали ее видеть многие поколения и какой она останется навсегда. Совершенное время ощущает себя зенитом, вершиной стольких эпох несовершенных, предварительных, пробных, ступенька за ступенькой ведущих к зрелой полноте. С вершины кажется, что все предшествующее жило единственно лишь бесплодной мечтой и несбыточной надеждой, что это были времена неутоленной жажды, пламенных упований, вечного «доколе» и жестокого разлада мечты с явью. Таким виделось XIX веку Средневековье. И вот настает день, когда вековые, иногда тысячелетние чаяния, похоже, исполняются - жизнь вобрала их в себя и следует их воле. Мы на желанной вершине, у заветной цели, в зените времени! Вечное «доколе» преобразилось в «наконец-то» [2, с. 55].

Наконец-то, желаемое «совершенное время» пришло. Это чувство начинает овладевать человечеством уже в XIX веке, который философ уже называет «самодовольным». Мимо этого самоощущения человека не мог пройти 3. Фрейд. Невозможно не процитировать имеющее к этому отношение его суждение. Именно он нашел самый точный образ для понимания ситуации, в которой человек оказался. «С давних времен человек создавал себе идеальное представление о всемогуществе и всезнании, воплощением которых были его боги. Им он приписывал все то, что было ему запрещено. Можно даже сказать, что боги были его культурными идеалами. Теперь он очень близко подошел к достижению этих идеалов, он сам сделался чуть ли не богом. Правда, лишь настолько, насколько человеческий здравый смысл вообще признает эти идеалы, достижимыми. В одних случаях они совершенно неисполнимы, в других - наполовину. Человек стал, так сказать, богом на протезах, величественным, когда употребляет все свои вспомогательные органы, но они с ним не срослись и доставляют ему порой еще немало хлопот» $[3$, c. 89$]$.

А что же способствовало такому состоянию и самосознанию человека? Наверное, тут задействовано много факторов. Но нас сегодня будет интересовать один из них - машина. Вот и 3. Фрейд под протезами подразумевает технологии. Отвечая на вопрос по поводу того, что способствовало радикальным изменениям и новому самосознанию человека, 3. Фрейд перечисляет множество технических изобретений, свидетельствующих об активном вторжении машины в человеческую жизнь. Техника создала для человека протезы, без которых он уже не может обойтись. «Всеми своими орудиями человек усовершенствует свои органы - как моторные, так и сенсорные - или же раздвигает рамки их применения, - пишет 3. Фрейд - моторы предоставляют в его распоряжение гигантские силы, употребляемые, подобно его мускулам, в различных целях; пароход и самолет делают беспрепятственными передвижения по воде и по воздуху; очки корректируют недостатки хрусталика глаза; телескоп делает возможность видеть на огромные расстояния; с помощью микроскопа преодолевается граница видимости, положенная строением нашей сетчатки. Человек создал фотокамеру - инструмент запечатления текучих зрительных впечатлений; граммофонная пластинка делает то же самое со звуковыми

International Culture \& Technology Studies, Vol. 6, No. 2 
впечатлениями. И то и другое суть материализации его способности запоминания, памяти. С помощью телефона он слышит на таком расстоянии, которое считалось невероятным даже в сказках: письменность с самого начала представляла собой речь отсутствующих; жилище - эрзац материального лона, первого и, может быть, доныне желанного обиталища, в котором мы пребываем в безопасности и так хорошо себя чувствуем» [3, с. 89].

Как мы убеждаемся, у 3. Фрейда в связи с машиной уже появляется эскиз истории коммуникации, которую позднее в более развернутом виде представит М. Маклюен. Полагаю, что все мы являемся носителями этого самого восторженного отношения к машине. Мы, поколение интернета, по инерции продолжаем испытывать ту же самую эйфорию, что возникла с утверждением мировосприятия, которое Ю. Хабермас обозначил как модерн, хотя мы-то по инерции все еще называем это мировосприятие Просвещением. На дворе давно уже развернулась переоценка этого самого модерна. Вспыхнуло настроение, получившее выражение в постмодерне как в его философских, так и эстетических формах. Кажется, что к сегодняшнему дню угасло не только настроение модерна, но угасло и или угасает настроение постмодерна. Последние события уже обещают возврат к тому, что общества в XX веке уже проходили и, следует сказать, этот возврат может происходить не без активного участия технологий. А мы все еще мыслим в соответствии с инерцией, и, обретая протезы, продолжаем ощущать себя богами.

Но подтверждает ли это жизнь? Может быть, пора уже сделать экскурсы в историю вторжения машины в жизнь человечества, которая ведь началась еще в Древней Греции [3], а, может быть, еще раньше. Но экскурсы даже не в историю техники, а в историю того, как она в разные эпохи воспринималась и оценивалась. Может быть, эти ретроспекции помогут более трезво взглянуть и на наши сегодняшние отношения с машиной. Так вот, оптимизм по поводу прихода машины имел место не всегда. А оборотной стороной модерна было открытие своего времени как декаданса. Это настроение уже приходит в середине XIX века с философией А. Шопенгауэра и с полной силой проявляет себя к концу этого столетия в философии Ф. Ницше. Стало быть, несмотря на возникающее самодовольство человека модерна, его подсознание свидетельствовало, что это оптимистическое настроение человек, возомнивший себя властелином Вселенной, как никогда в истории, растерял. Но и как не оказаться в таком положении, если он вышел за пределы традиции. Он вышел за пределы культуры, в соответствии с которой существовали все предшествующие поколения. Он лишился образцов, которые до этого определяли его сознание и поведение. А что такое эти образцы, как не культура. «Впервые в истории, - пишет Х. Ортега-и-Гассет - возникает эпоха без эталонов, которая не видит позади ничего образцового, ничего приемлемого для себя, - прямая наследница стольких веков, она тем не менее похожа на вступление, на рассвет, на детство. Мы озираемся, и прославленный Ренессанс нам кажется провинциальным, узким , кичливым и - что греха таить - вульгарным» [2, с. 59].

Конечно, конечно, самодовольный человек XIX века порывает свои связи с историей еще не окончательно. Это подтверждает и Х. Ортега-и-Гассет. «... Пресловутый XIX век, при всем сознании своего совершенства - а может быть, в силу такого сознания, - был неотделим от прошлого, чьи плечи ощущал под собой; по сути, он видел в себе осуществленное прошлое» [2, с. 59]. Более того, в XIX веке, ближе к его концу продолжалась начатая романтиками реабилитация Средневековья. Она имела место еще в первых десятилетиях этого столетия, но с особой силой - в русской религиозной философии и теургической эстетике, а также в неоромантизме или символизме. Однако новая вспышка модерна, ставшая основой русской революции 1917 года, эту альтернативу смыла, что стало основой возникающего тоталитаризма. Выражением духа нового времени стал футуризм, а сводить его лишь к одному из художественных течений не приходится. На этой основе вновь торжествует исключительно оптимистическое и восторженное отношение к технике. Оно, конечно, является универсальным, общемировым.

Но если история в ее традиционном понимании перечеркнута, а традиционное понимание истории связано с культурой, то ее можно мыслить уже по-другому. А именно, как историю возникновения и воздействия на человека машины. Вводим машину в историю и попробуем продемонстрировать как она разрушает и перестраивает культуру. Проиллюстрируем эту новую интерпретацию истории с помощью проекта, вызванного к жизни французским поэтом, сценаристом и кинотеоретиком 20-х годов прошлого века Б. Сандраром. На полстолетие опережая М. Маклюена, Б. Сандрар предпринимает набросок морфологии культуры, понимаемой как

Культура и технологии, Том 6, № 2 
морфология коммуникации, и в эту историю он вписывает кино, с которым пока еще неизвестно что делать. Какие средства ему предшествуют и какие за ним последуют. Для Б. Сандрара появление кино - такое же грандиозное завоевание культуры, каким была в свое время письменность и книгопечатание. Все основные сдвиги в истории коммуникации Б. Сандрар называет «мировыми революциями». Ну, раз так, то, понятно, без машины историю представить уже невозможно. Революциями, конечно же, в истории медиа, хотя слово «медиа» еще не употреблялось.

Согласно Б. Сандрару, первая революция произошла в Древней Греции в связи с возникновением письменности, что привело к человеческой творческой активности, ее удвоению и возрастанию. Возникновение в микенском мире письма связано с принципом организации дворцовой жизни, с бюрократическим аппаратом, функцией которого был учет и контроль. Эта система основывалась на применении письменного учета и учреждения архивов. Во дворец Кносса письмо принесли писцы с Крита, начавшие служить микенской династии. Но письмом пользовались еще в строго замкнутых группах. Это письмо исчезло вместе с микенской цивилизацией, когда произошло вторжение в Грецию дорийцев. Грекам пришлось письменность вызывать к жизни второй раз. Но это была уже другая письменность, и у нее были другие функции. Давая характеристику микенской цивилизации, Ж.-П. Вернан пишет следующее. «Когда греки к концу IX века до новой эры вновь откроют ее (письменность - Н. Х.), переняв на сей раз у финикийцев, это будет не просто письменность другого фонетического типа, но явление радикально иной цивилизации. Она уже не будет составлять особой специальности писцов, но станет элементом общей культуры. Социальное и психологическое значение письменности также изменится, став прямо противоположным: письмо больше не имеет целью учреждать на потребу царю архивы в тайниках дворца; отныне оно приобретает публичный характер и делает объектом всеобщего обсуждения различные аспекты общественной и политической жизни» [5, с. 57]. Овладение письмом продолжилось в Риме. Римляне, как пишет Б. Сандрар, гравируют свою историю на медных или оловянных табличках. В Александрии появляется библиотека.

По Б. Сандрару, вторая «мировая революция» произойдет в середине XV века в связи с появлением печатного станка. В 1455 году в Майнце Гутенберг печатает «первую великую европейскую книгу - Библию. Но его деятельность начинается раньше. Историки датируют ее началом 1449 года. Гутенберг изобретает подвижный шрифт, а потом его отливает в металле. Начинается наводнение мирового пространства печатными книгами. Множатся университеты и библиотеки. Наука выходит из стен монастырей. Появляются газеты. Образование демократизируется, и культура утончается. Благодаря печати народы входят в более тесное соприкосновение. Наконец, согласно Б. Сандрару, на рубеже XIX-XX веков начинается третья мировая революция. Человечество движется к новому синтезу человеческого духа, и этому способствует возникновение кинематографа. «Шлюзы нового языка открыты. Буквы нового букваря, бесчисленные, толпятся. Все становится возможным. Евангелие Завтрашнего дня, Дух будущих законов, Научная эпопея, Предвосхищающая легенда, Видение четвертого измерения Бытия, все Скрещения! Смотрите! Революция» [6, с. 38-42].

Любопытно, что бы мог сказать Б. Сандрар о появлении интернета. Наверняка он провозгласил бы четвертую мировую революцию, которая ведь тоже в истории технологий не ставит точку. Хотя М. Маклюен очень старался, чтобы следующей радикальной революцией в истории медиа воспринималось телевидение. Так, Б. Сандрар убеждает нас в том, что возникновение кино - это и в самом деле следующая революция. А вот Л. Манович, затрагивая вопрос об истории медиа, утверждает, что следующая мировая революция произошла с появлением не кино, а фотографии. Вот и теоретик медиа В. Эрнст пишет, что эпоха медиа начинается с фотографии и даже указывает дату начала этой эпохи, а именно, 1839 год [8]. А за фотографией появляется фонограф как устройство для сохранения сигналов, а затем техническая воспроизводимость движения в форме кинематографа. Этому тоже соответствует дата - 1895 год.

Кстати, заодно В. Эрнст констатирует, что концептуально смысл открытий в сфере медиа был разъяснен лишь позднее, только в трудах М. Маклюена. Суждение о том, что медиа начинаются фотографии, спорно. А как же быть с письменностью и печатью, которые М. Маклюен включает в историю медиа? Но у В. Эрнста свои резоны. Для него медиа идентифицируется лишь с появлением технических изобретений. Смысл этих технических

International Culture \& Technology Studies, Vol. 6, No. 2 
изобретений он поясняет так. «Поэтому медиаистория не является историей техники, понятой как аппараты и машины, но является одновременно и археологией графического разума, которая в контексте фотохимических, электромеханических и электронных медиа до сих пор была предметом конструктивного интереса лишь инженеров» [7, с. 145]. То, что следующая революция началась с фотографии, может быть, даже верно. Не то, чтобы кино не выводимо из фотографии (это делалось, и примером тому может служить теория 3. Кракауэра), но фотография как-то всегда оказывалась в стороне, на обочине истории искусства. Замечательный теоретик фотографии А. Руйе справедливо пишет, что фотография была признана полноправным культурным и художественным явлением совсем недавно, лишь примерно в 1970-е годы [9].

Сегодня возникает возможность нового прочтения и фотографии, и следующих за ней медиа как множества фаз в истории становления того, что сегодня называют виртуальной реальностью [11, с. 11]. Мы вспоминаем восторженные наброски истории медиа, принадлежащие Б. Сандрару, спустя столетие. За это время должна была появиться и четвертая мировая революция. Она и появилась, и мы сегодня ее называем цифровой революцией или медиа революцией. Констатацию этого события именно как революции мы находим у теоретика медиа (а каждая революция порождает своих теоретиков) Л. Мановича. Вот как Л. Манович новое средство медиа соотносит с существующей культурой. Не разделяя мысль о том, что компьютеры будут использоваться исключительно для консервации культурного архива, он пишет: «Скорее, современная медиареволюция - как переключение культурных практик в режим производства, распространения данных и коммуникации за счет компьютеров - фундаментально повлияет на развитие общества. Она перевернет представления о культуре - примерно так же, как изобретение печатного станка в XV веке и фотографии в XIX. Мы только начинаем фиксировать эффекты распространения компьютеров, но уже понимаем: эта новая революция коренным образом изменит современность и многие, если не все, виды деятельности. Все-таки прежние технологические революции были менее фундаментальны и влияли исключительно на особенности культурной коммуникации, обращения конкретных артефактов культуры. Изобретение печатного станка трансформировало нормы распространения медиа, а фотография изменила правила производства статичных изображений. Однако революция компьютерных медиа затрагивает все стадии и этапы производства и дистрибуции культурных объектов, включая покупку, управление, хранение и распространение любых типов артефактов, а также всех типов медиа: текстов, статичных и динамичных изображений, звуков, спатиальных конструкций» $[10$, c. 54$]$

Предложенная Б. Сандраром периодизация возникла под воздействием того восторженного восприятия кино, которое имело место в первые десятилетия прошлого века. Конечно, это не могло не определить экскурсы в историю и поиски аналогичных ситуаций. Так, возникает набросок той концепции, которую, спустя десятилетия, предложит М. Маклюен. Но у М. Маклюена следствием очередной мировой революции, если выражаться языком Б. Сандрара, является все же возникновение телевидения. А что уж говорить об интернете. Но каждый раз, когда появляется новое средство медиа, возникает необходимость в морфологическом анализе, т.е. в нахождении места нового средства в истории медиа. Так, например, возникновение книгопечатания обязывало найти место этому новому средству медиа в истории. В связи с этим возникает любопытная закономерность, которую важно зафиксировать и мотивировать. В момент возникновения, на своей ранней стадии каждое новое средство медиа приоткрывает и даже пробует реализовать то, что можно осуществить в полном выражении лишь позднее. Но все же такие попытки можно фиксировать. Это обстоятельство позволяет понять связь между разными средствами медиа как разными фазами в становлении виртуальной реальности.

Такую периодизацию предлагает, например, Ф. Барбье, пытаясь осмыслить природу изобретения Гутенберга и бумажной цивилизации в целом. Ф. Барбье не склонен изолировать историю печати как одно из средств медиа от остальных средств. В начале своей книги он даже предупреждает, что его целью является подобрать ключ к пониманию медийной революции, характерной для 2000-х годов. Во-первых, этим суждением Ф. Барбье подчеркивает, что облагодетельствованный многими технологическими новинками человек XX века все же оказывается в состоянии неопределенности и неосознанности той ситуации, в которой он оказывается. А потому исторические экскурсы могут ему помочь осмыслить последствия нового антропологического сдвига, связанного с интернетом. Иначе говоря, исторический анализ медиа у

Культура и технологии, Том 6, № 2 
Ф. Барбье превращается в определяющий. Во-вторых, как в свое время Б. Сандрар не мог избежать эмоционального отношения к очередному антропологическому сдвигу, связанному с появлением кино, так и Ф. Барбье не может оценивать сдвиг, связанный с интернетом, не прибегая к понятию «мировая революция». В-третьих, возникновение книгопечатания Ф. Барбье включает в мировосприятие, которое с легкой руки Ю. Хабермаса сегодня называют модерном. Это безусловно важный момент. В связи с этим приходится даже уточнять происхождение слова «модерн». С этой точки зрения открытие Гутенберга стало следствием возникновения нового мировоззрения. Но к этому его функция не сводится. С другой стороны, оно становится двигателем внедрения нового мировоззрения в сознание людей. В-четвертых, очень важно, что историю книгопечатания Ф. Барбье соотносит с историей возникновения и функционирования в культуре знака, пытаясь дать новому изобретению семиотическое истолкование, что будет актуальным и для интерпретации появляющихся последующих медиа, например, кино и не только. Для Ф. Барбье революция, связанная с печатью, это в то же время и семиологическая революция. Эта мысль есть и в суждениях Л. Мановича, упрекающего теоретиков за то, что они избегают анализа семиотических кодов компьютерных медиа [10, с. 54].

Но и это еще не все. Наконец, в-пятых, Ф. Барбье, опережая историю, прямо говорит о том, что печатная книга является заметным продвижением в направлении становления виртуализации. Перечисляя позитивные признаки книгопечатания, он, между прочим, пишет следующее: «Наконец, принцип семиологии упрощает не только хранение и обработку информации, но также оказывается особенно благоприятным для развития интеллектуального инструмента, каким является виртуальность. Этот пункт еще только ждет своего исследователя, тогда как создание «бумажного мира», исходя из которого будут развиваться опыт (включая литературные опыты: роман) и выводы, оказывающиеся одним из ключевых элементов современности» [11]. В самом деле, Ф. Барбье можно понять: все это такие сдвиги, которые заслуживают того, чтобы их обозначить, как сдвиги революционные. Экскурс в историю книгопечатания, сделанный современным исследователем медиа, актуален и объясним. «Если двухтысячные годы, когда телекоммуникация и информация превратились в банальность, - эпоха очевидной «медиареволюции» с точки зрения истории, это не первая подобная революция: другие эпохи тоже были отмечены глубокими изменениями в системах социальной коммуникации» [11, с. 11]. Включая историю коммуникации в общую историю медиа, Ф. Барбье все же углубляется именно в историю медиа, а в этой истории он в конечном счете выделяет два ключевых периода - XV век, когда к производству печатного текста оказалась готовой технология, и XIX век, когда развертывалась промышленная революция и возникала масса читателей, что сделало неизбежностью тиражирование печатных текстов.

Для чего там много внимания мы уделяем истории в новом, т.е. технологическом ее варианте? Прежде всего для того, чтобы вернуться к мысли о проблематичности, в которой оказался человек модерна. Он пребывает в своем самодовольстве еще и с помощью технологий. На наш взгляд, вопрос о взаимоотношениях технологии и культуры может помочь выявить оборотную сторону, т.е. не оптимистическую сторону восторженного восприятия технологий. Попробуем соотнести машину с коммуникацией, с творчеством, с культурой и, конечно, с искусством. Но перед этим поставим два вопроса - об отношении технологии к эстетической и художественной сфере и о необходимости исторического изучения медиа. Во-первых, ответим на вопрос, почему людям искусства нужно заниматься технологиями. Может быть, мы по-прежнему продолжаем воспринимать технику, как ее воспринимали в галантном XVIII веке, когда она выводилась за пределы культуры. Но уже ближе к концу этого столетия отношение человека к миру становится все более утилитарным. На все начинают смотреть сквозь призму пользы, что констатирует Ф. Шиллер. Это ощущает И. Кант. Дух наступающей эпохи позитивизма обязывает философа открыть и обосновать игровой космос и осмыслить его как противостояние пользе, вообще, машине. Это послужило основой становления эстетики. Вместе с открытием игрового и эстетического начинается открытие проблематики культуры и культуры как предмета исследования.

Может быть, возникновение эстетики уже свидетельствует о том, что противодействием утилитаризму является то, что предметом внимания впервые становится культура. Для погружения в эту проблематику XIX век не был удачным. Даже те открытия, касающиеся

International Culture \& Technology Studies, Vol. 6, No. 2 
культуры, что были сделаны в XVIII веке (например, Гердером и не только) остались пребывать втуне. До XX века, пока не станет проблематичной, как говорит Шпенглер, вся мировая история. В XX веке и, еще точнее, во второй его половине все обратились к культуре. Но на самом деле, в культуре ли тут дело? Но если дело не в культуре, то в чем же? В чем-то таком, что способна помочь разрешить культура. А что это? Ответ задержим. Мы еще не знаем о всех возможностях культуры. Но точно также мы не знаем, как утверждает М. Хайдеггер, и того, что такое техника. Но мы должны быть благодарны М. Хайдеггеру уже за то, что он не то, чтобы открыл, а просто осознал, что познание смысла техники будут способствовать художественные эксперименты. Поэтому повторим еще раз: возникновение эстетики во многом была реакцией на технологии и на позитивизм в целом. В связи с идеей выведения техники из потаенности в открытость М. Хайдеггер недвусмысленно формулирует функцию искусства, приобретающую в эпоху технологий все большее значение. «Поскольку существо техники не есть нечто техническое, сущностное, - пишет М. Хайдеггер — осмысление техники и решающее размежевание с ней должны произойти в области, которая, с одной стороны, родственна существу техники, а, с другой, все-таки фундаментально отлична от него. Одной из таких областей является искусство» $[12$, c. 238$]$.

Стоит ли удивляться, что сегодня в сфере искусства деятельность этого рода является особенно интенсивной, о чем свидетельствует и практический опыт, и множество творческих работ. Все это и подтверждает вывод философа. Во-вторых, история технологий нам важна для осознания того, что каждая новая технология не может быть осознана самостоятельно, изолированно от других, что было, например, характерно для кино. Ведь очевидно, что дискуссии о том, является ли кино искусством, длилось десятилетия. Но изучение кино было изолировано от общей истории медиа. Более глубокое освоение смысла кино связано с нахождением им места в едином гештальте. А этим гештальтом является виртуальная реальность, входящая в наш мир в виде процесса и фаз в этом процессе, а этими фазами являются фотография, кино, телевидение, а также и предшествующие этим средствам медиа фазы в истории виртуализации.

Продемонстрировав перспективы ретроспективного подхода к новой истории, сведенной к истории машины, и обнаружив коммуникативные, эстетические и художественные аспекты этой истории, которая в то же время является и историей медиа, мы возвращаемся к констатации актуальных общефилософских и общеэстетических проблем, требующих обсуждения. К таким актуальным проблемам относится проблема взаимоотношений между технологией и культурой. Это наиболее общий уровень осознания смысла, функционирования и последствий технологии. Без этого общего вопроса будет трудно оценивать то, что происходит под воздействием технологий в искусстве и в эстетике, которые будут частными вопросами. Находятся ли культура и технологии в гармонических отношениях или же эти отношения конфликтны?

Впервые значимость техники обращает на себя внимание в XIX веке. Что касается предшествующего XVIII века, то, как пишет Шпенглер, ее тогда вообще не замечали, а если и замечали, то считали не заслуживающей внимания. Судя по всему, со временем это привело к тому, что Шпенглер назовет проблематичностью всей мировой истории [12, с. 455]. И уж, конечно, от галантного века тянется традиция презрительного отношения к технике и выведению ее за пределы культуры. Таково происхождение конфликтности в отношениях культуры и технологии. Конечно, необходимо уходить от поверхностных оценок техники, что имели место в XVIII веке. Хотя и в них есть определенный смысл. Техника - это не культура. Так вопрос ставит Й. Хейзинга, и, казалось бы, с ним невозможно не согласиться. Однако нельзя все же не видеть, несмотря на их несходство, но и некоторого между ними сходства. На первый взгляд, в основе этого сходства лежит одинаковое отношение к природе. Как и культура, техника - искусственное порождение. То и другое - это творение человеческих рук. Культура возникает как результат разрыва между человеком и природой. Человек перестает быть частью природы и обретает по отношению к ней самостоятельность. И это показатель развития человека, его свободы. Показатель прогресса человека и истории. В этом смысле техника как искусственное порождение этот разрыв продолжает.

Эта ситуация особенно остро предстает в массовых, т.е. индустриальных обществах, когда преемственность в сохранении традиций нарушается. Техника продолжает разрыв с природой и доходит до того, что разрывает и с самой культурой, еще сохраняющей связь с природой. Не случайно на определенном этапе истории возникает понятие цивилизации как альтернативы

Культура и технологии, Том 6, № 2 
культуре. Как замены культуре. Но что означает разрыв с культурой? Отвечая на этот вопрос, мы узнаем больше и о самой культуре. То, что мы обычно подразумеваем под культурой, связано с тем, что здесь разрыв с природой уже происходит, но своих крайних форм еще не достигает. Человек одновременно существует и в природе, и в культуре. Он и экспериментирует, и обращен в будущее, он развивает в себе творческое, индивидуальное начало, но одновременно является частью природы. Чтобы уйти от абстракции, напомним определение культуры по Шпенглеру. Он считал, что культура существует до тех пор, пока человек сохраняет связь с землей. Проблемы с культурой возникают в городах, когда разрыв с культурой очевиден.

Конечно, тут следует иметь в виду эволюцию самой культуры. Она то разрыв с природой доводит до предела, то, оказываясь у порога надлома и распада, реабилитирует в себе природное начало. Нам, искусствоведам, это известно по смене художественных стилей в истории. В моменты кризиса культуры человек способен возвращаться к природе, о чем свидетельствует эпикурейская и руссоистская традиции, восстанавливающие равновесие [14]. Почему же человек вынужден восстанавливать гармонию? Да потому, что культура - это вторая природа человека, а в ней объективируется, реализуется не все, что существует в самой природе. Время от времени культура лишается спонтанности, незапрограммированности и потому мертвеет. И тогда реабилитация природы в культуре становится неизбежной.

Что же касается техники, то здесь такой возврат к природному началу уже невозможен. Поэтому техника с самого начала связана не столько с культурой, сколько с цивилизацией. С вторжением машины в человеческую жизнь начинается история цивилизации. В технике разрыв доводится до своего крайнего завершения. Техника - это одна из тенденций культуры, которая здесь гипертрофируется и становится основной. И потому техника способна обернуться смертью культуры, исчезновения в ней спонтанного, игрового и, в общем, гуманистического духа. С другой стороны, культура не может порвать с техникой, поскольку техника развивает до предела заложенные в культуре возможности. Техническое, машинное начало есть уже в самой культуре, ибо она - создание самого человека. Технологии превращают то, что в культуре является потенциальным, в реальное. Уже одно это может вселить надежду, что между культурой и технологией возможен синтез.

В этом смысле весьма показательна применяемая к технике идея органопроекции, высказанная еще в XIX веке Э. Каппом, а затем изложенная П. Флоренским. Каждое техническое изобретение по отношению к человеку не является внешним. Оно лишь овнешняет то, что является для него внутренним. Технология является способом выведения во вне, в том числе, в сознание и в культуру того, что в человеке содержится, но что им не осознается. Осознание происходит через овнешнение, через выражение внутреннего с помощью предметно-чувственных форм. Органопроекция, как ее представляют в философии техники, - это не только продолжение и расширение различных органов человеческого тела (рук, ног, мозга, нервной системы и т.д.), но и способ познания этого тела с помощью проецирования происходящих в нем процессов на технические устройства. «Прежде всего, - пишет П. Флоренский - далеко не все органы собственного своего тела мы знаем. Тело наше не может считаться познанным, что однако не мешает творческому воображению техника проецировать его в технику и т.п. Стороны нашего тела или т. п. органы, которые анатомии макро- или микроскопической и физиологии еще неизвестны. Следовательно, не только допустимо, но и следует ждать увидеть в технике такие орудия, которых прототипа органического мы еще не нашли» [15, с. 161].

Но почему же принцип органопроекции имеет отношение только к телесности, как следует из этого суждения? Однако П. Флоренский, выявляя смысл техники, все же настаивает на ее соотнесенности исключительно с биологией. Продолжая свою мысль, П. Флоренский пишет: «Если изучение организмов есть ключ к техническому изобретению, то и обратно, технические изобретения можно рассматривать как реактив к нашему самопознанию. Техника может и должна провоцировать биологию, как биология - технику. В себе и вообще в жизни открываем мы еще не осуществленную технику; в технике - еще не изученные стороны жизни» [15, с. 161]. Принцип органопроекции подводит к разгадке потаенного смысла техники. Однако в таком исключительно телесном его понимании он уязвим и неполон. Чем уязвима идея органопрекции? Да тем, что она исключительно физиологична и биологична. Потому она и появилась в философии техники.

International Culture \& Technology Studies, Vol. 6, No. 2 
В момент, когда эта идея появилась, науки о культуре еще не было. Осмысление этого принципа в культурологическом смысле быть не могло. Человек не исчерпывается телесным началом. Раз мы сопоставляем технику с культурой, а культура также связана с духовным, как и с телесным началом, то нам не обойтись без постановки вопроса и о духовной, а не только телесной проекции. Тут нам необходимы не только 3. Фрейд, Э. Капп и П. Флоренский, сколько Гегель. Короче, нам нужна феноменология Духа Гегеля и ее не только эстетическое, но и культурологическое истолкование технологии. Гегель проделал уже то, к чему позднее призовет Н. Бердяев. А он призывал не к отторжению техники, не к охранению культуры от техники, а к их синтезу. Пожалуй, для нас эта формула сегодня приемлема. Во всяком случае, хотя бы как продолжение осмысления технологий.

Ведь что, собственно, положил Гегель в основу становления в истории Духа? В основе его истории - проекция внутреннего, духовного на внешнее, чувственное, материальное. Иначе говоря, то, что мы называем культурными и художественными формами, Гегель рассматривает как проекцию духовного на чувственное. Этот механизм есть опредмечивание. Опредмечивание применительно к духовному — то же, что в философии техники понимается под органопрекцией, но уже не в биологическом и анатомическом, телесном смысле. Однако все ли сказал Гегель об этой самой проекции духовного на чувственное, которую он называет опредмечиванием? Не следует ли этот гегелевский механизм рассмотреть с точки зрения общества, которое способно довести действие этого механизма проекции до абсурда? Не является ли то, что экзистенциалисты и неомарксисты в XX веке назвали отчуждением как оборотной стороной опредмечивания?

Попробуем понять процессы виртуализации в истории, в том числе, как они развертывались в фотографии, кино и на телевидении и как они развертываются сегодня в интернете именно с помощью проекции внутреннего на внешнее, в чем, собственно, состоит и смысл органопроекции в технике. Философская концепция Гегеля поможет понять, как позитивные, так и возможные негативные стороны виртуализации. Даже не негативные стороны. Скорее ограничения. Мы имеем ввиду прежде всего проекцию внутреннего на внешнее и выражение этого внутреннего через внешнее как признаки того, что с некоторых пор в гуманитарных науках называют «отчуждением». А это и есть гегелевская традиция. Только вот сам Гегель еще не подходил к тем смыслам отчуждения, которые заставила открыть в этом механизме реальность эпохи тоталитарных режимов. Гегель, как совершенно понятно, совсем не касался технологий, поскольку их еще не существовало. Его концепцию можно применить исключительно к истории эстетики и культуры, в том числе, и к истории искусства.

Но вот этот процесс овнешнения внутреннего с помощью техники имеет не только психологическую сторону и не касается только индивида. Бессознательное становится сознательным - это логика объективации не только индивидуальных процессов, но и процессов культуры. В культуре ведь тоже имеет место свое бессознательное - культурное бессознательное, и оно может осуществляться в технологическом формате. Этого вопроса теоретики органопроекции не ставили. Но есть необходимость его поставить. Это важно для понимания сдвигов в художественных сферах. Ведь искусство первым делает прорыв к культурному бессознательному и его может представить в предметных формах. Вообще, несмотря на то, что мы разводим культуру и технику, тем не менее, как свидетельствует принцип органопроекции, культуру и технику тоже сближает соотношение внутреннего и внешнего, а именно это обстоятельство и положено в основу гегелевской феноменологии. Ведь культура, как и техника, тоже является, как уже отмечалось, искусственным порождением. Она непосредственно из природы не вытекает. Наоборот, она восполняет в природе то, чего человеку недостает, чтобы выживать. Технологическое в ней присутствует с самого начала.

Теперь следующий, вытекающий из взаимоотношений между культурой и технологией вопрос. Культуру создает человек, но когда он ее создал, то уже культура начинает создавать человека. Но ведь, как уже нами отмечалось, технология - тоже искусственное порождение, как и культура. Ее тоже создает человек. Но, как и культура, она тоже претендует на создание человека. Получается ли? Вот это и следует проследить и осмыслить. Дело тут совсем не ограничивается появлением роботов, к которым человечество шло, начиная с античности. Ведь что удивительно, эта логика овнешнения внутреннего прослеживалась в древних восточных империях, в античности, затем, начиная со Средневековья, в западном мире. В эту историю Гегель вписал и историю эволюции художественных форм, пытаясь обнаружить, в каких культурах и эпохах

Культура и технологии, Том 6, № 2 
внутреннее и внешнее достигали гармонии, а в каких между ними можно было фиксировать разлад. Эта мысль Гегелем положена в основу его фундаментальной концепции эстетики. Самое удивительное, что в эту логику философа мы можем включить и те художественные формы, что в результате технологической революции стали возможными.

Если это так, то история медиа также не может не предстать перед нами не только в исключительно позитивном духе. Правда, такой истории мы пока еще не имеем. Каждое новое средство медиа мы воспринимаем как самостоятельное, а если и сопоставляем его с другими, предшествующими средствами, то делаем это поверхностно. Л. Манович усматривает такую закономерность: в начальные эпохи каждое средство медиа обходится без теории. Сущность нового средства медиа длительное время не осознается [10, с. 37]. Не осознается, поскольку эти самостоятельные средства медиа можно постичь лишь как последовательно появляющиеся фазы в истории становления того, что мы называем виртуальной реальностью. Когда-то, ставя вопрос о необходимости принять меры, способствующие оздоровлению больной и угасающей культуры, Й. Хейзинга не мог пройти мимо ее отношений с технологиями. Можно ли с помощью технологий преодолеть упадок культуры, в котором она в XX веке оказалась, способствовать ее развитию и, наоборот, способны ли технологии наносить культуре вред. К его выводу следовало бы прислушаться.

Этот вопрос Й. Хейзинга ставил применительно не только к технике, но и к науке, поскольку технологические новшества своим появлением обязаны науке. И та, и другая несут ответственность за негативные последствия для культуры, за появление и углубление дегуманизации, которую можно наблюдать в ХX веке. Й. Хейзинга, конечно, не отрицает их благотворного влияния на общественную жизнь, но все же в своей работе он констатирует: «Сделавшая столь мощный скачок наука вместе со своей младшей сестрой, технологией, уже с XIX века претендует на то, чтобы их отождествляли с культурой. Но мы, к сожалению, знаем, что очень высокие формы научного развития могут сочетаться с ужасающим варварством» [16, с. 251]. В другом месте выдающийся историк культуры прямо говорит о возможности использования техники в разрушительных целях и разрушительных применительно к культуре. «техника каждый день производит все новые чудеса, но никто больше не чувствует к ней доверия, потому что она уже показала, что в гораздо большей степени способна разрушить, чем уберечь» $[16$, c. 340$]$.

С этой точки зрения показательны работы Н.Бердяева и О. Шпенглера. Так Шпенглер, говоря о том, что конечной целью технического прогресса должен быть perpetuum mobile, способствующий тому, чтобы человек занял место Бога. «Вечный двигатель был бы окончательной победой над Богом и над природой (deus sive natura): малый мир творит сам себя и, подобно большому миру, движим своей собственной силой, послушной только человеку. Самому построить мир, самому быть Богом - вот фаустовская мечта, из которой проистекли все проекты машин, насколько возможно приближавшиеся к недостижимой цели perpetuum mobile» $[13$, с. 484]. Однако не все обстоит столь благополучно. Дело в том, что машина в прошлом всегда вызывала страх, и ее воспринимали как выдумку дьявола. Но, может быть, эти времена ушли в прошлое? Может быть, причины подобного восприятия машины уже отсутствуют? Да, нет, Шпенглер приходит к другому выводу. Он формулирует: «Властелин мира сделался рабом машины» [13, с. 486].

Вот тут-то как раз и становится актуальным обсуждение оборотной стороны эйфории от технологии. Демоническое начало в восприятии техники с течением времени не исчезает. А вот еще более серьезное обобщение Шпенглера. Он говорит: «Сама цивилизация стала машиной, которая все делает или желает делать по образу машины» [13, с. 488]. Этот вывод невольно вызывает ассоциации. О машине ли, о цивилизации ли здесь идет речь? Может быть, о том самом тоталитаризме, т.е. о социуме, имитирующем машинное начало? К аналогичным выводам подводит и Н. Бердяев. Техника в процессе своего развития приобретает чудовищную власть, способствуя дегуманизации. «В своей исторической судьбе, - пишет Н. Бердяев - человек проходит разные стадии, и всегда трагична эта судьба. Вначале человек был рабом природы, и он начал героическую борьбу за свое охранение, независимость и освобождение. Он создал культуру, государство, национальные единства, классы. Но он стал рабом государства, национальности, классов. Ныне вступает он в новый период. Он хочет овладеть иррациональными общественными

International Culture \& Technology Studies, Vol. 6, No. 2 
силами. Он создает организованное общество и развитую технику, делает человека орудием организации жизни и окончательного овладения природой. Но он становится рабом организованного общества и техники, рабом машины, в которую превращено общество и незаметно превращается сам человек» $[17$, с. 522].

Казалось бы, речь идет лишь о промышленности. Причем, тут история медиа? А при том, что уже одно из первых средств такого рода, а именно, письменность вызывало сомнения. Такие сомнения мы находим у Платона. Сошлемся на беседу между изобретателем письменности Тевтом и царем Тамусом в диалоге Платона «Федр». Так, Тамус в рассказе Сократа по поводу памятливости, которой якобы способствует письмо, выразил сомнение. Это было даже не сомнение в полезности письмен, а констатация их вреда. Очень важно вдуматься в смысл его аргументации. Ведь сегодня очевидно, что интернет как фантастическое средство получения информации развивается параллельно упадку общей грамотности. «В души научившихся им они (письмена - Н. Х.) вселят забывчивость, так как будет лишена упражнения память: припоминать станут извне, доверясь письму, по посторонним знакам, а не изнутри, сами собою. Стало быть, ты нашел средство не для памяти, а для припоминания. Ты даешь ученикам мнимую, а не истинную мудрость. Они у тебя будут многое знать понаслышке, без обучения, и будут казаться многознающими, оставаясь в большинстве невеждами, людьми трудными для общения; они станут мнимомудрыми вместо мудрых» [18, с. 216].

Что имел в виду Сократ, когда говорит о «мнимой мудрости», приобретаемой с помощью письменности, разъясняет цитата из книги Х. Дж. Чейтора «От написанного к напечатанному», повлиявшей в свое время на выводы М. Маклюена. По признанию канадского философа, Х. Дж. Чейтору он обязан появлением на свет его книг. А Х. Дж. Чейтор говорит об ослаблении памяти под воздействием печатного текста. «Наша память значительно ослаблена воздействием печатного текста. Мы знаем, что нет необходимости «перегружать память» всем тем, что можно найти, просто сняв с полки книгу. Когда же большая часть населения не владеет грамотой, а книги являются раритетом, требуется цепкость памяти, значительно превосходящая память современного европейца. Например, индийские студенты способны выучить наизусть учебник и повторить его на экзамене слово в слово. Устная передача священных текстов служила надежным средством сохранения их неизменными. Говорят, что если бы все рукописные и отпечатанные экземпляры Ригвед были утеряны, текст все равно можно было бы восстановить до буковки. А ведь это - почти «Илиада» и «Одиссея» вместе взятые» [19, с. 139].

Спрашивается, причем же тут эстетика и причем искусство? Обратим в связи с этим внимание на то, как У. Эко, разрабатывая свою теорию «открытого произведения», открывает эту вторую сторону технологий, связанную с отчуждением в формах технологий. Кстати, именно У.Эко демонстрирует потребность в тех смыслах отчуждения, которые нам известны по философии не только Сартра, но и Маркса. Правда, обращаясь в сторону технологий, У. Эко иллюстрирует свою мысль с помощью литературы, но в том числе, он приводит примеры и из кино. Вернемся к идее протеза, с помощью которого 3. Фрейд пытался понять взаимоотношения техники и человека. Прибегая к этой метафоре, 3. Фрейд пользовался представлениями, сложившимися к этому времени в философии техники. Мы попытались эти представления изложить, обращаясь к П. Флоренскому. Но до сих пор мы лишь констатировали вопрос об обратной стороне вторжения технологий в духовную сферу, намекая на отрицательный эффект. В этом смысле мы ссылались на авторитет Платона и Руссо. Но пора все же в этот механизм углубиться и его рассмотреть уже не в технологическом, а в философском смысле.

Конечно, традиция органопроекции идет от Э. Каппа и подхватывается П. Флоренским, суждение которого мы выше процитировали. Но это еще не философия. Философия органопроекции в культурологическом смысле начинается с Гегеля, сопоставившего технологии со становлением культуры. Но применительно к Гегелю понятие технологии следует понимать в культурологическом, а, еще точнее, в художественном смысле. У Гегеля внутренние процессы Духа овнешняются в стилях культуры и в художественных стилях. Это чисто эстетический и художественный смысл органопроекции. Не случайно эта идея феноменологии Духа так убедительно оказалась представлена в его фундаментальном сочинении, посвященном эстетике, в котором он фиксирует последовательно сменяющиеся в истории формы выражения как эстетические формы. Все эти фазы представляют собой ступени овнешнения становящегося Духа, а, следовательно, в истории культуры тоже развертывается нечто, сходное с органопроекцией. Но

Культура и технологии, Том 6, № 2 
эта проекция уже не ограничивается физиологией и анатомией, скажем, удлинением и расширением в пространстве различных органов человека, а распространяется на всю культуру, культура же уподобляется технологии.

Понимая принцип действия технологических открытий, мы получаем ключ к пониманию функционирования культуры. Поэтому феноменологический проект Гегеля можно рассматривать культурологическим проектом. Как бы то ни было, механизм отчуждения впервые был обнаружен и отрефлексирован все же тем же Гегелем. Другое дело, что акцент в этом открывшемся ему механизме философ поставил на позитивных последствия отчуждения как значимого творческого механизма, способствующего прогрессу разума и культуры. Этим, собственно, и исчерпывается его интерпретация феномена отчуждения. Однако последующая эпоха интереса к этому механизму не утрачивает. Поскольку понятие, обозначающее этот механизм, оказалось одним из ключевых понятий новой философии, то в причинах его популярности следует разобраться.

$\mathrm{XX}$ век никак невозможно представить столетием, дающим повод для оптимизма. Поэтому в понимании данного вопроса с Гегелем можно разойтись. Эпоха с присущим ей чувством катастрофизма смогла разглядеть в открытом Гегелем механизме, в том числе, и негативный смысл. Конечно, конечно, никто не отрицал позитивных сторон технологии, тем более, что, как нами уже показано, со временем технологические открытия трансформируются в факты культуры, и обратная сторона проблемы как бы снимается. Наоборот, всеми этими новшествами человек ХХ века сумел воспользоваться и свою жизнь значительно улучшил. Но пришел момент отрефлексировать обратную сторону действия этого механизма, чего сам Гегель не сделал. Это осуществили мыслители, выразившие умонастроение, владеющее человечеством в постреволюционную эпоху, в период между двумя мировыми войнами. И еще точнее, углубление в проблематику отчуждения произошло в кругах той интеллигенции, в которой возрождались и развивались идеи, называемые экзистенциализмом.

Однако на этом пути от Гегеля к экзистенциалистам возникает выдвинутая XIX веком с присущим ему начавшимся омассовлением, фигура Маркса, предложившего собственную, можно сказать, апокалиптическую интерпретацию механизма отчуждения. Смысл этой интерпретации тесно связан со сверхзадачей политических идей Маркса, а она заключалась в непременном революционном разрешении всех возможных в обществе конфликтов, что, конечно, предстает не единственным вариантом их разрешения. Как Гегель использовал это понятие для понимания движения Духа, т.е. для универсальной своей концепции, так Маркс его использует для понимания своих идей, связанных с возможностью появления бесклассового общества. В чем же в этом случае заключается расхождение между Гегелем и Марксом в понимании отчуждения? Дело все в том, что с механизмом отчуждения Гегель обращается чисто философски, не привязывая его к конкретному историческому времени и к конкретному обществу, избегая заключений политического характера. У него отчуждение предстает как опредмечивание форм сознания, существующего в виде идей и образов, во внешних или в предметно - чувственных формах, что имеет своим следствием совершенствование контакта человека с внешним миром, и, в конечном счете, совершенствование и развитие самого человека, который, как пишет 3. Фрейд, постепенно на основе всего этого превращается в Бога.

Однако вместо того, чтобы предстать Богом, новый человек предстал в реализации утопических идей варваром, агрессивным существом, обернувшим свою агрессию против себе подобных. Хотя первоначально идея приходит в благородной форме. А способом оправдания такого его поведения оказалась, вопреки Марксу, теория Маркса. Реальность однако идеи Маркса не подтверждала и даже наоборот, свидетельствовала об их утопичности. В гегелевской трактовке акцент ставится на отчуждение как способе развития человека, освобождающегося от всех тех барьеров, которые это развитие тормозит. В такой интерпретации отчуждения получает выражение основной признак эпохи модерна. Но при таком рассмотрении в тени оказывается производимое, вызываемое к жизни в процессе деятельности второе слагаемое отношения «человек - создаваемая им вещь». А эта вещь - плод физических и духовных усилий человека, обособляясь от человека, приобретая самостоятельность, может быть обращена против человека. Когда и при каких обстоятельствах это случается? На этот вопрос Гегель не отвечал, да он его перед собой и не ставил. Он не был социологом.

International Culture \& Technology Studies, Vol. 6, No. 2 
Однако суждение Г. Зиммеля, представляющего социологию, свидетельствует о том, какие выводы можно было сделать, читая Гегеля. «Нам - пишет Г.Зиммель - противостоят бесчисленные объективации духа, произведения искусства и социальные нормы, институты и познание, подобно управляемым по собственным законам царствам, притязающие на то, чтобы стать содержанием и нормой нашего индивидуального существования, которое в сущности не знает, что с ними делать, и часто воспринимает их как бремя и противостоящие ему силы» $[20$, c. 490$]$.

Что касается Маркса, то он пытается понять, как эта созданная человеком вещь способна функционировать и какими могут быть последующие ее взаимоотношения с человеком. Вот почему У. Эко обращается к Марксу. А это обстоятельство зависит уже не от человека и не от вещи, а от контекста, в котором находится и человек, и вещь. Контекста социального и, что часто упускается из вида, контекста культуры. А поскольку из границ культуры в эпоху модерна выходит не только технология, но и само общество, то можно себе представить, какую опасность представляет создаваемый человеком с благими намерениями этот самый предметный мир, если он оказывается в таком обществе. Этот вопрос Маркс поставил применительно к тому обществу, который имел место в XIX веке, т.е. к индустриальному, а, если выражаться словами Маркса, капиталистическому обществу, которое, используя технологию, начинает эпоху беспрецедентного тиражирования производимых вещей. И вот здесь-то, в этом самом обществе вещь выступает уже не только символом творческого дара человека и свидетельством его творческого духа, а способом, направленным против человека и его свободного развития.

Этот вопрос занимает не только Г. Лукача, но и У. Эко, который пытается воспользоваться понятием отчуждения применительно к анализу постиндустриального общества как и функционирующего в нем искусства. У. Эко обращает внимание на то, что отчуждение Маркс не сводит к объективации, что характерно для Гегеля. Отталкиваясь в принципе от Гегеля, от выявленного Гегелем механизма опредмечивания, Маркс показывает, как этот механизм может функционировать в обществе. В случае объективации человек выражает себя в своей деятельности и стремится упорядочить и усовершенствовать мир. Интерпретация отчуждения Марксом связана с другим. Процитируем те выводы, которые делает У. Эко, читая Маркса. «Однако когда механизм этого мира одолевает человека, который уже не может признавать его за свое собственное произведение, то есть когда человеку уже не удается подчинить созданные им вещи своим целям, но, напротив, в каком-то смысле он сам подчиняется их целям (которые могут отождествляться с целями других людей), тогда он оказывается в ситуации отчуждения. Именно его собственное произведение определяет, что он должен делать, как себя чувствовать, чем становиться. Это отчуждение тем больше, чем сильнее он (претерпевая воздействие) продолжает верить, что действует сам и воспринимает ситуацию, в которой живет, как наилучший из возможных миров» $[21$, c. 293],

Но если рассмотрение этого вопроса Маркс переводит с чисто философского уровня на уровень социологический, то получается, что с этой точки зрения, может быть, уязвим не только Гегель, но уже и сам Маркс. Ведь того общества, которое наблюдал и функционирование которого пытался осмыслить Маркс, вроде бы уже не существует. Общество заметно либерализируется и, следовательно, острые вопросы, связанные с отчуждением, кажется исчезают. Но если не исчезают, то хотя бы смягчаются. Конечно же, они не исчезают, что своим следствием не может не иметь возникновение ситуации, в контексте которой появляются, например, фильмы Антониони, свидетельствующие о том, как глубоко во взаимодействия между людьми, да и в духовный мир самого человека это отчуждение проникает. Собственно, в своих фильмах Антониони ставит вопрос об антропологических последствиях отчуждения. Так что одним возвращением к видению сути отчуждения от Маркса к Гегелю тут ничего не объяснить.

Если мы будем ждать от Антониони , что герои в его фильмах будут обсуждать проблемы, связанные с отчуждением, то это ожидание не оправдается. Об этом ничего не будет сказано. Герои его фильмов этот вопрос не обсуждают. Да, собственно, они сами не осознают, что с ними происходит. Один из его фильмов, а именно, «Затмение» начинается с игры на бирже, когда люди внезапно осознают, что они проигрываются и лишаются средств к существованию. Казалось бы, какое отношение этот эпизод, обязывающий вспомнить о сочинении Маркса «Капитал», к антропологии? Но в том-то и дело, режиссер стремится показать, что невидимые силы нового духа пронизывают психологию героев. Между тем, едва ли можно назвать какой-то другой фильм,

Культура и технологии, Том 6, № 2 
который бы прояснил антропологический смысл отчуждения больше, чем фильм Антониони. В его фильмах рассказывается история мужчины и женщины, которые встречаются, а затем расстаются. Потом героиня встречает другого мужчину, и из этой встречи тоже ничего не проистекает. Все дело в создаваемой режиссером атмосфере. Над героями «тяготеет нечто суровое, неотступное, объективное, надчеловеческое» [21, с. 336].

Вот как интерпретирует У. Эко фильм Антониони и какие смыслы из него извлекает, а это и есть смыслы, выражающие его мысль об отчуждении. «Этот фильм, рассказывающий о невозможной и ненужной любви между ненужными и невозможными персонажами в общем способен сказать нам больше о человеке и мире, в котором он живет, чем большое, мелодраматическое полотно, на котором рабочие, одетые в комбинезоны, переживают игру чувств, разворачивающуюся по правилам драмы XIX века, так что мы готовы поверить, будто гдето над переживаемыми ими противоречиями существует порядок, эти противоречия оценивающий» [21, с. 336]. Все дело в том, что цель, которую режиссер перед собой поставил, с помощью традиционных форм организации повествования достигнутой быть не может. Для принесения своей мысли режиссер должен разрушить традиционный сюжет, выстроенный в соответствии с жесткой причинно-следственной логикой. Ведь не только психология персонажей и их поступки, но и организация сюжета в фильме тоже оказывается во власти отчуждения.

Сюжет - слагаемое способа выражения, а этот способ - результат овнешнения и опредмечивания по Гегелю. Это объясняет, почему постмодернисты превозносят строение произведения по принципу ризомы. «И вот режиссер раскрывает эту ситуацию нравственной и психологической неопределенности неопределенностью монтажа картины; одна сцена следует за другой без какой-либо связи, взгляд беспричинно и бесцельно падает на какой-либо предмет. Антониони на уровне форм принимает ту самую ситуацию отчуждения, о которой хочет говорить, но раскрывая ее через структуру своего дискурса, он овладевает ею и доносит до сознания зрителя» [20, с. 336]. Так мы обнаруживаем, что эффект органопроекции, понимаемый уже не только в анатомическом, телесном, но и в духовном смысле, во многом определяет принцип действия медиа, но он также может формировать построение художественных произведений. Технические внедрения в культуру, перестраивая ее на свой лад, также определяют художественные процессы.

В заключение всего выше сказанного вернемся снова к сомнениям Платона, высказанным по поводу письменности. Но на этот раз эту мысль мы воспроизведем в изложении К. ЛевиСтроса. Суждение, которое делает этот выдающийся ученый, во многом определивший развитие гуманитарных наук в XX веке, связано не с Платоном, а с Ж.-Ж. Руссо, высказывающимся по поводу отчуждения с помощью опять же письма и печати. Комментируя Руссо, К. Леви-Строс позволяет себе высказать мысль, относящуюся, конечно, ко всем средствам медиа, а они, принося в мир много полезного и человеку необходимого, в то же время порождают и проблемы. И мы сегодня, вынужденные в ситуации пандемии свести живые формы общения к минимуму, как никогда, эту мысль понимаем и разделяем. «Наши отношения с другими людьми лишь изредка и лишь отчасти основываются на некоем глобальном опыте - на конкретном понимании субъекта другим человеком - пишет К.Леви-Строс - Чаще всего они складываются из косвенных реконструкций на основе письменных документов. Нас воссоединяет с прошлым не устная традиция, предполагающая живой контакт с конкретными людьми, рассказчиками, священниками, мудрецами или старейшинами, но книги: они переполняют библиотеки, где ученые кропотливым трудом восстанавливают образ их авторов. А в нашей нынешней жизни мы общаемся с подавляющим большинством своих современников через разного рода посредников письменные документы или административные механизмы, которые несомненно сильно расширяют наши контакты, но одновременно лишают их подлинности. Это особенно характерно для отношений между гражданами и властями. Мы не будем играть в парадоксы, отрицательно определяя тот огромный переворот, который был вызван изобретением письма. Однако нельзя не учесть, что оно принесло человечеству много хорошего, но отняло у него что-то очень важное» [22, с. 286]. Судя по всему, те новые средства медиа, которые в будущем обязательно появятся, из этого заколдованного круга человечество не выведут.

International Culture \& Technology Studies, Vol. 6, No. 2 


\title{
Литература
}

[1] Блок А. Ирония. Собрание сочинений в 8 томах. Том 5. М-Л.: Государственное издательство художественной литературы. 1962.

[2] Ортега - и - Гассет Х. Восстание масс // Ортега - и - Гассет Х. Избранные труды. - М.: Издательство «Весь мир». 1997. 704 с. С. $43-232$.

[3] Фрейд 3. Недовольство культурой // Психоанализ. Религия. Культура. М.: Ренессанс. 1991. 296 с. С. 66 134.

[4] Хренов Н. Марионетка как феномен культуры: мифологические и антропологические аспекты // Старые и новые медиа: формы, подходы, тенденции XX1 века. Издательские решения. По лицензии Ridero. 2019. 175 c. C. $141-175$.

[5] Вернан Ж. - П. Происхождение древнегреческой мысли // М.: Прогресс. 1988. 224 с.

[6] Сандрар Б. Азбука кино // Из истории французской мысли. Немое кино. 1911- 1933 гг. - М.: Искусство. 1988. 318 c. C. $38-42$.

[7] Эрнст В. Время медиа: понятия, археология, наука // Медиа между магией и технологией. Москва, Екатеринбург: Кабинетный ученый. 2014. 330 с.

[8] Хренов Н. Новая визуальность как проблема культуры // М.: СПб.: Центр гуманитарных инициатив. 2019. $416 \mathrm{c}$.

[9] Руйе А. Фотография между документом и современным искусством. СПб.: Клаудберри. 2014. 712 с.

[10] Манович Л. Язык новых медиа. М.: Ад Маргинем Пресс. 2018. 400 с.

[11]Барбье Ф. Европа Гутенберга. Книга и изобретение западного модерна (X11 - ХУ1). М.: Издательство Института Гайдара. 2018. 496 с.

[12] Хайдеггер М. Время и бытие. Статьи и выступления. М.: Республика. 1993. 447 с.

[13]Шпенглер О. Человек и техника // Культурология. ХХ век. Антология. М.: Юрист. 1995. 703 с. С. 454 494.

[14]Хренов Н. Трагедия эпикуреизма: эпохи оттепели в истории культуры // Terra Aestheticae. 2020. № 1/5. C. 42-78.

[15] Флоренский П. Органопроекция // Русский космизм: Антология философской мысли. М.: Педагогика Пресс. 1993.

[16] Хейзинга Й. Тени завтрашнего дня. Человек и культура. Затемненный мир. Эссе. СПб.: Издательство Ивана Лимбаха. 2010. 456 с.

[17] Бердяев Н. Человек и машина (Проблема социологии и метафизики техники) // Бердяев Н. Философия творчества, культуры и искусства. В 2 - х т., // М.: Искусство. ИЧП «Лига». 1994. Т. 1. 544 с С. 499 - 523.

[18] Платон. Сочинения в 3 - х т. Т. 2. М.: Мысль. 1970. 613 с.

[19] Маклюен М. Галактика Гутенберга. Сотворение человека печатной культуры. Киев. Ника - Центр Эльга. Издательский дом Дмитрия Бураго. 2003. 431 с.

[20]Зиммель Г. Кризис культуры // Зиммель Г. Избранное. В 2-х т. Т. 1. Философия культуры. М.: Юрист. $1996.671 \mathrm{c}$.

[21] Эко У. О способе формообразования как отражении действительности // Эко У. Открытое произведение. Форма и неопределенность в современной поэтике. СПб.: Symposium. 2006. 412 с. С. 291- 350.

[22] Деррида Ж. О грамматологии. М.: Издательство «Ad Marginem». 2000. 512 с.

\section{The Relationship Between Technology and Culture: Aesthetic and Cultural Aspects}

\author{
N. A. Khrenov
}

Russian State Institute of Cinematography (VGIK), Russia

\begin{abstract}
Virtual reality. This article is devoted to the history of the emergence of various media, the meaning of which is revealed only in our time, when there are post-modern media in the form of the Internet. The author proposes to consider the later media, namely, photography, cinema, television, etc., not only as art forms, which is how they have been studied so far, and not only as independent aesthetic phenomena, but as consistently emerging forms of a single gestalt, which should be understood as virtual reality. From this point of view, the history of media can be represented as consisting of such phases of the virtualization process as the photographic, cinematic, television, etc.phases. The process of virtualization goes deep into history, when language, writing, and printing arise. The article focuses on the media that began with the emergence of photography in the 19th century, which became an important milestone in the emergence of sign systems no longer in verbal, but in visual forms. In this regard, the author proves that the study of virtual reality involves the use of
\end{abstract}


a semiotic approach. Turning to the well-known principle of organ projection in the philosophy of technology, the author comes to the conclusion that the bodily forms of organ projection must be supplemented with spiritual ones, which requires philosophical and aesthetic approaches. In this regard, the author refers to the phenomenology of Hegel, in which the principle of projection of inner into outer, subject-sensitive, what is the meaning of the Hegelian principle involves vneshneye already not in the flesh but in the spirit. As the author proves, the Hegelian principle is the most effective for the aesthetic development of technologies. True, Hegel did not resort to the concept of "projection". He referred to this mechanism of externalization as objectification. The subsequent appeal to this concept led to the identification of the reverse side of the principle of objectification associated with the phenomenon of alienation. According to the author, a deeper understanding of the virtualization process unfolding in the $\mathrm{X} 1 \mathrm{X}$ century inevitably leads to the need to consider the media from the perspective of alienation, which is the reverse side of their functioning.

Keywords: media, mediarevolution, technology, civilization, sign, semiotic approach, culture, organoprotective, virtualization, objectification, alienation, photography, cinema, television, Internet, writing, typography, modern, Gestalt, Cendrars, Kapp, Florensky, Freud, Barbier, Spengler, Hegel, Gutenberg, Heidegger, the manovich, Plato, Marx, Eco

\section{References}

[1] Blok A. Ironiya. Sobranie sochineniy v 8 tomakh, tom 5. M-L.: Gosudarstvennoe izdatel'stvo khudozhestvennoy literatury. 1962.

[2] Ortega y Gasset x. The Revolt of the Masses / / Ortega y Gasset X. Selected works. M.: Publishing House "All the world". 1997. 704 p.

[3] Freud Z. Discontent with culture // Psychoanalysis. Religion. Culture. M.: Renaissance. 1991. 296 p.

[4] Khrenov N. The puppet as a cultural phenomenon: mythological and anthropological aspects // Old and new media: forms, approaches, trends of the XX1 century. Publishing solutions. Under the Ridero license. 2019. $175 \mathrm{p}$.

[5] Vernan J.-P. The origin of ancient Greek thought // M.: Progress. 1988. 224 p.

[6] Cendrard B. Azbuka kino // From the history of French thought. Silent movies. 1911-1933 Moscow: Iskusstvo. $1988.318 \mathrm{p}$.

[7] Ernst V. Time media: concepts, archeology, science // Media between magic and technology. Moscow Yekaterinburg: Cabinet scientist. 2014. P. 145-330.

[8] Khrenov N. Novaya visualnost ' kak problema kultury [New visual identity as a problem of culture]. 2019. 416 p.

[9] Rouillet A. Photography between document and contemporary art. St. Petersburg: Cloudberry. 2014. 712 p.;

[10] Manovich L. The language of new media. Moscow: Ad Marginem Press. 2018. 400 p.

[11]Barbier F. Gutenberg's Europe. The book and the invention of Western Modernism (X11-HU1). Moscow: Publishing House of the Gaidar Institute. 2018. 496 p.

[12] Heidegger M. Time and being. Articles and speeches. M.: Republic. 1993. 447 p.

[13] Spengler O. Chelovek i tekhnika [Man and technology]. XX century. Anthology. Moscow: Yurist. 1995.703 p.

[14] Khrenov N. The tragedy of epicureanism: epochs of thaw in the history of culture // Terra Aestheticae. 2020. No. $1 / 5$. P. 42-78.

[15]Florensky P. Organoprojection // Russian cosmism: An Anthology of philosophical thought. M.: PedagogikaPress. 1993.

[16] Huizinga Y. Shadows of tomorrow. Man and culture. A darkened world. Essay. St. Petersburg: Ivan Limbach Publishing House. 2010.

[17] Berdyaev N. Man and Machine (The problem of sociology and metaphysics of technology) // Berdyaev N. Philosophy of creativity, culture and art. In 2 vols. M.: Art. PPI "League". 1994. Vol. 1. 544 p.

[18] Plato. Essays in 3 volumes. Vol. 2. M.: Thought. 1970.

[19] McLuhan M. Gutenberg galaxy. The creation of a human print culture. Kiev. Nika-The Center of Elga. Dmitry Burago Publishing House. 2003. 431 p.

[20] Simmel G. The crisis of culture // Simmel G. Izbrannoe. In 2 volumes. Vol. 1. Philosophy of culture. Moscow: Yurist. 1996. $671 \mathrm{p}$.

[21] Eco U. About the method of shaping as a reflection of reality // Eco U. Open work. Form and uncertainty in modern poetics. St. Petersburg: Symposium. 2006. 412 p.

[22] Derrida J. About grammatology. M.: Publishing House "Ad Marginem". 2000. 512 p. 